\title{
T1b Stage Finding
}

National Cancer Institute

\section{Source}

National Cancer Institute. T1b Stage Finding. NCI Thesaurus. Code C48722.

A general term that refers to a TNM finding of a primary tumor limited to the site of growth. The definition of T1b TNM finding depends on the specific type of cancer that it refers to; for example, for breast cancer it refers to a primary tumor that is more than $0.5 \mathrm{~cm}$, but not more than $1.0 \mathrm{~cm}$ in greatest dimension; for kidney cancer it refers to a primary tumor that is more than $4 \mathrm{~cm}$, but not more than $7 \mathrm{~cm}$ in greatest dimension; and for thyroid cancer it refers to a primary tumor that is more than $1 \mathrm{~cm}$ but not more than $2 \mathrm{~cm}$ in greatest dimension. 